\title{
In situ preparation of well-dispersed CuO nanocatalysts in heavy oil for catalytic aquathermolysis
}

\author{
Ming Chen ${ }^{1}$. Chen $\mathrm{Li}^{1}$ · Guo-Rui Li ${ }^{1}$ - Yan-Ling Chen ${ }^{1}$. Cheng-Gang Zhou ${ }^{1}$
}

Received: 3 March 2018 / Published online: 13 March 2019

(c) The Author(s) 2019

\begin{abstract}
We developed an in situ synthesis strategy for preparing well-dispersed $\mathrm{CuO}$ nanoparticles as aquathermolysis catalyst for viscosity reduction in Shengli heavy oil (China). A Cu(OH) ${ }_{2}$-contained microemulsion was employed as a carrier to disperse the precursor $\mathrm{Cu}(\mathrm{OH})_{2}$ to the heavy oil phase. Under aquathermolysis condition $\left(240{ }^{\circ} \mathrm{C}, 2.5 \mathrm{MPa}\right.$ of $\left.\mathrm{N}_{2}\right)$, the $\mathrm{Cu}(\mathrm{OH})_{2}$ precursors would first be converted in situ to well-crystallized and size-homogeneous $\mathrm{CuO}$ nanoparticles naturally, catalyzed by which the viscosity of Shengli heavy oil could be reduced as much as $94.6 \%$; simultaneously, $22.4 \%$ of asphaltenes were converted to light components. The agglomeration of the in situ prepared monoclinic $\mathrm{CuO}$ nanoparticles could be negligible throughout the catalytic reaction. Based on the characterization results of ${ }^{1} \mathrm{H}$ NMR, elemental analysis and GC-MS of oil samples before and after catalytic aquathermolysis, the mechanism for viscosity reduction of heavy oil in the catalytic system was investigated.
\end{abstract}

Keywords $\mathrm{Cu}(\mathrm{OH})_{2}$-contained microemulsion · In situ preparation $\cdot \mathrm{CuO}$ nanocatalyst $\cdot$ Catalytic viscosity reduction $\cdot$ Heavy oil

\section{Introduction}

The rapidly increasing energy demand compels the urgent development of methods for high-efficiently utilization of unconventional energy reserves such as heavy oil (Muraza and Galadima 2015). However, the high viscosity and poor liquidity of heavy oil present a very challenging hurdle. Reducing the viscosity of heavy oil to improve its liquidity for feasible exploitation of heavy oil becomes the most critical issue (Guo et al. 2016; Kapadia et al. 2015). Catalytic aquathermolysis combines the catalytic function with steam at high temperature and pressure, where steam serves as the hydrogen radical donor to promote the decomposition of S-containing compounds and macromolecules, providing

Edited by Xiu-Qin Zhu

Yan-Ling Chen

ylchen@cug.edu.cn

$\triangle$ Cheng-Gang Zhou

cgzhou@cug.edu.cn

1 Faculty of Materials Science and Chemistry, China University of Geosciences, Wuhan 430074. People's Republic of China an enhanced catalytic efficiency (Clark and Hyne 1984). Due to its low cost and high efficiency, catalytic recovery of heavy oil has been recognized as a promising technology for exploitation which has attracted numerous efforts (Bano et al. 2015; Hou et al. 2017; Li et al. 2016; Ren et al. 2015). Transition metal (TM) species, including Fe (Galukhin et al. 2015; Mohammad and Mamora 2008; Qin and Xiao 2013), $\mathrm{Cu}$ (Chao et al. 2012; Li et al. 2013), Ni (Wang et al. 2014; Yusuf et al. 2016), Mo (Chen et al. 2009) and Co (Cao et al. 2016; Wu et al. 2016a, b), are effective catalytic centers when coordinated with certain oil-soluble or water-soluble ligands which enable satisfactory viscosity reduction efficiency from 62 to $90 \%$. Recently, nanosized metal and metal oxides based on these TMs, which possess large specific surface area and high catalytic efficiency, have become a focal interest as aquathermolysis catalysts. Several nanocatalysts, involving $\mathrm{Fe} / \mathrm{FeO}$ (Yang et al. 2014), $\mathrm{Fe}_{2} \mathrm{O}_{3}$ (Ovalles et al. 2015), $\mathrm{Fe}_{3} \mathrm{O}_{4}$ (Abdullah 2014), $\mathrm{NiO}$ (Noorlaily et al. 2013), $\mathrm{Cu} / \mathrm{CuO}$ (Shokrlu and Babadagli 2014), $\mathrm{ZrO}_{2}$ (Wang et al. 2012) and $\mathrm{MoO}_{3}$ (Shuwa et al. 2015), are capable of achieving acceptable viscosity reduction. It has been recognized that $\mathrm{Cu}$-based oxide behaves better than other TMs in the same catalytic conditions (Shokrlu and Babadagli 2014). 
In fact, heterogeneous $\mathrm{Cu}$-based oxides have already been demonstrated to be efficient catalysts for desulfurization (Nair and Tatarchuk 2010; Wu et al. 2016a, b) and photocatalysis (Jiang et al. 2017; Nezamzadeh-Ejhieh and Amiri 2013). However, when serving as catalyst of aquathermolysis of heavy oil, the catalytic efficiency of $\mathrm{Cu} / \mathrm{CuO}$ nanoparticles is highly correlated with the particle size and dosage (Greff and Babadagli 2011; Shokrlu and Babadagli 2014). In fact, one can easily envision that, under the high temperature during aquathermolysis, the nanoparticles would be easily agglomerated to larger ones which will decrease the catalytic activity considerably. On the other aspect, the dispersion of nanoparticles to the high-viscous oil phase is technically difficult, which should be another governing factor that determines the final viscosity reduction efficiency. Consequently, transporting the heterogeneous nanocatalysts to the heavy oil phase and preventing them from being aggregated emerge as crucial issues. Hashemi et al. (2013, 2014) suggested that the excellent lipophilicity of a microemulsion makes it a suitable carrier to transfer catalyst to the oil phase. Ni-metal nanocatalysts were in situ prepared for heavy oil hydrocracking, which converts $70 \%$ of resins and $50 \%$ of asphaltenes to aromatics and saturates at $370{ }^{\circ} \mathrm{C}$ under $11 \mathrm{MPa}$ of $\mathrm{H}_{2}$. Furthermore, the preparation of microemulsion catalyst is easy to implement under moderate conditions. Inspired by these results, we prepared a $\mathrm{Cu}(\mathrm{OH})_{2}$-contained microemulsion as a carrier to disperse the $\mathrm{Cu}(\mathrm{OH})_{2}$ precursors to the heavy oil phase. Under our catalytic aquathermolysis conditions $\left(240{ }^{\circ} \mathrm{C}, 2.5 \mathrm{MPa}\right.$ of $\left.\mathrm{N}_{2}\right)$, the precursors would be in situ naturally transformed to $\mathrm{CuO}$ nanoparticles. Catalyzed by the monoclinic $\mathrm{CuO}$ nanocatalysts, the viscosity of Shengli heavy oil could be reduced as much as $94.6 \%$, during which $22.4 \%$ of asphaltenes were converted to light components. Our results expand application of microemulsions in aquathermolysis and propose a highly efficient and deployable approach to develop $\mathrm{Cu}$ or other TM oxide-based nanocatalysts for reducing the viscosity of heavy oil via catalytic aquathermolysis. This strategy may provide an alternative for steam injection stimulation of heavy oil.

\section{Experimental section}

\subsection{Hydroxide microemulsion precursor preparation}

All analytic grade chemicals purchased from Sinopharm Chemical Reagent were used without further purification. $\mathrm{Cu}(\mathrm{OH})_{2}$-contained microemulsion was prepared by a reverse microemulsion method. Firstly, $2.00 \mathrm{~g}$ SP-80, $2.00 \mathrm{~g}$ TW-60, $2.00 \mathrm{~mL}$ isoamylol and $10.00 \mathrm{~mL}$ diesel were mixed and thoroughly dispersed ultrasonically for $20 \mathrm{~min}$ to obtain an oil phase. Secondly, $2.00 \mathrm{~mL}$ of $\mathrm{NaOH}(1.50 \mathrm{~mol} / \mathrm{L} \mathrm{aq})$ and $2.00 \mathrm{~mL}$ of $\mathrm{Cu}\left(\mathrm{NO}_{3}\right)_{2}(0.75 \mathrm{~mol} / \mathrm{L} \mathrm{aq})$ were added into two equivalent oil phases under vigorous stirring, to form an alkali microemulsion and metal salt microemulsion, respectively. Subsequently, the $\mathrm{NaOH}$ microemulsion was mixed with the $\mathrm{Cu}\left(\mathrm{NO}_{3}\right)_{2}$ microemulsion in a water bath at $40{ }^{\circ} \mathrm{C}$ for $2 \mathrm{~h}$ to form $\mathrm{Cu}(\mathrm{OH})_{2}$. The $\mathrm{Cu}(\mathrm{OH})_{2}$-contained microemulsion precursor (labeled as $\mathrm{CuME}$ ) was prepared for catalytic aquathermolysis. Upon mixing the two microemulsions, the droplets collide and coalesce, allowing the mixing of the precursor to produce nanoparticles (Santra et al. 2001). The Formation of $\mathrm{Cu}(\mathrm{OH})_{2}$ nanoparticles was visually realized by the appearance of a blue color of the microemulsion mixture, which could be directly applied in aquathermolysis of heavy oil. For comparison, we also conduct a blank experiment to prepare the $\mathrm{CuO}$ nanoparticles under the same conditions $\left(240{ }^{\circ} \mathrm{C}, 2.5 \mathrm{MPa} \mathrm{N}_{2}, 24 \mathrm{~h}\right)$ without the presence of heavy oil.

\subsection{Catalytic aquathermolysis}

The laboratory catalytic aquathermolysis experiments were carried out for $100 \mathrm{~g}$ oil samples with an oil:water ratio of 8:2 and $3 \mathrm{~mL}$ CuME in a $500 \mathrm{~mL}$ FYX-0.5 high-pressure reactor for $24 \mathrm{~h}$ at $180-260{ }^{\circ} \mathrm{C}$ under an atmosphere of $2.5 \mathrm{MPa} \mathrm{N} \mathrm{N}_{2}$. After reaction, the mixture was dumped into a $150-\mathrm{mL}$ beaker. The viscosity of the oil samples before and after reaction was measured with a BROOKFIELD DV-II+ programmable viscometer at $50{ }^{\circ} \mathrm{C}$. The dehydration of the oil samples was conducted on an ultrasonic crude rapid dehydration instrument (BT-350, Hubei Broad Electronics Co. Ltd., China). The water contents of the dehydrated samples were determined with a Karl Fischer (Coulomb) SF101 tester (Precision Instrument Co. Ltd., Taizhou, Jiangsu, China) following the GB/T1146-2009 standard of People's Republic of China. The measured water contents of the samples, either before or after the catalytic aquathermolysis, are all below $0.002 \mathrm{wt} \%$ (Ren et al. 2015). The viscosity reduction efficiency was calculated by the formula $\left(\eta^{0}-\eta\right) / \eta^{0} \times 100 \%$, where $\eta^{0}$ and $\eta$ represented the viscosity of extra-heavy oil before and after aquathermolysis, respectively. As displayed in Table 1, an optimal viscosity reduction rate as well as acceptable energy consumption could be achieved at $240{ }^{\circ} \mathrm{C}$. For comparison, aquathermolysis of heavy oil only with $\mathrm{NaNO}_{3}$ or $\mathrm{CuO}$ was implemented under the same conditions. Similarly, all oil samples were dehydrated prior to measurement. The four components (saturated hydrocarbons $(\mathrm{SH})$, aromatic hydrocarbons $(\mathrm{AH})$, resins and asphaltenes) before and after reaction were separated from the oil samples by an $\mathrm{Al}_{2} \mathrm{O}_{3}$ chromatography column according to the industrial standard of China Petroleum SY/T 5119-1995. The catalyst was recovered from the heavy oil by dilution with toluene for further characterization. 
Table 1 The viscosity reduction efficiency of CuME at different temperatures $\left(180-260^{\circ} \mathrm{C}\right)$

\begin{tabular}{lcl}
\hline Temperature, ${ }^{\circ} \mathrm{C}$ & Viscosity, mPa s & $\begin{array}{l}\text { Viscosity } \\
\text { reduction effi- } \\
\text { ciency, } \%\end{array}$ \\
\hline- & $24,150 \pm 100$ & - \\
180 & $7088 \pm 140$ & $71.08 \pm 0.02$ \\
200 & $5090 \pm 100$ & $79.20 \pm 0.02$ \\
220 & $3020 \pm 80$ & $87.67 \pm 0.01$ \\
240 & $1300 \pm 40$ & $94.70 \pm 0.01$ \\
260 & $1076 \pm 30$ & $95.61 \pm 0.01$ \\
\hline
\end{tabular}

\subsection{Characterization}

The hydrodynamic diameter of the microemulsion was investigated using dynamic light scattering (DLS, Nano ZS90, Malvern, UK). The solids isolated from CuME and recovered catalyst were characterized with an X-ray diffractometer (XRD, D8-FOCUS, Bruker, Germany). The collected catalyst after aquathermolysis and the comparative $\mathrm{CuO}$ nanoparticles were characterized by transmission electron microscopy (TEM, Philips CM12, Holland). The $\mathrm{C}, \mathrm{H}, \mathrm{N}$ and $\mathrm{S}$ contents and structural information of resins and asphaltenes were measured with an elemental analysis instrument (EA, VARIO EL-2, Germany) and proton nuclear magnetic resonance spectroscopy (using tetramethylsilane (TMS) as internal reference and $\mathrm{CDCl}_{3}$ as solvent, ${ }^{1} \mathrm{H}$ NMR, BRUKER Ascend400, Germany), respectively. Light components and gas were analyzed on a gas chromatograph-mass spectrometry (GC-MS, Agilent GC7890AMSD5975C, USA, Column: Agilent 122-5562HP-5MS 5\% Phenyl Methyl Silox $30 \mathrm{~m} \times 250 \mu \mathrm{m} \times 0.25 \mu \mathrm{m}$ ).

\section{Results and discussion}

Based on DLS results displayed in Fig. 1, the size of the microemulsion droplets was uniform and mainly concentrated in the range 105-122 $\mathrm{nm}$. The morphological features of the separated catalysts after aquathermolysis were next examined with TEM. Figure $2 b$ shows that the particles were mostly round shaped with the diameters ranging from 5 to $10 \mathrm{~nm}$. No particle agglomeration was observed, suggesting that the microemulsion could achieve a good dispersion of the particles in the catalytic reaction system. XRD profiles of the particles separated from $\mathrm{CuME}$ and the aquathermolysis reaction indicated well-crystallized $\mathrm{Cu}(\mathrm{OH})_{2}$ and monoclinic $\mathrm{CuO}$ without impurity, respectively, as displayed in Fig. 3. According to this evidence, we can rationally conclude that the $\mathrm{Cu}(\mathrm{OH})_{2}$ precursors, dispersed by the microemulsion, have been converted in situ to $\mathrm{CuO}$ during aquathermolysis. In fact, since the conversion from $\mathrm{Cu}(\mathrm{OH})_{2}$ to $\mathrm{CuO}$ could

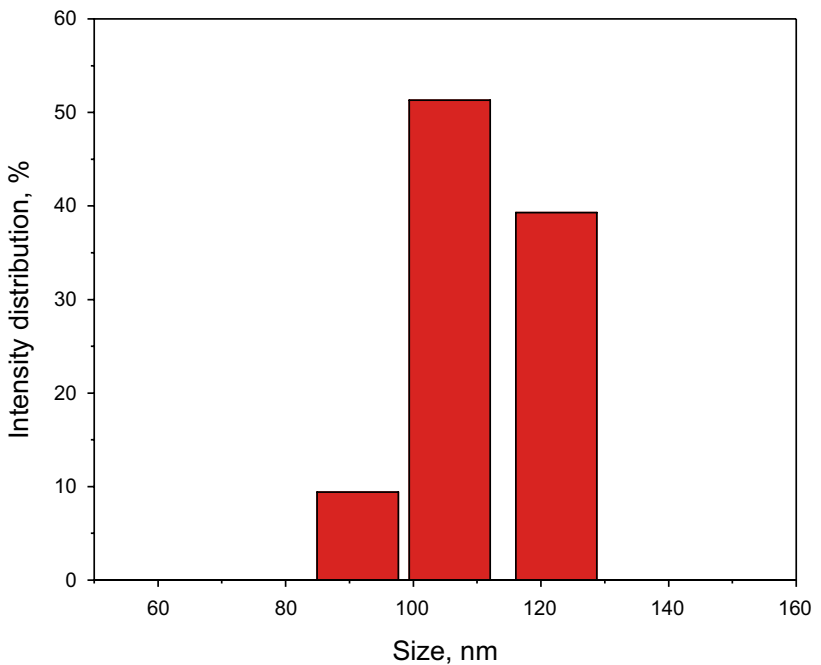

Fig. 1 DLS result of the $\mathrm{Cu}(\mathrm{OH})_{2}$-containing microemulsion droplets

occur at very low temperature $\left(60-120^{\circ} \mathrm{C}\right)(\mathrm{Lu}$ et al. 2004), while the microemulsion is unstable, the catalytic aquathermolysis performance should mainly originate from the $\mathrm{CuO}$ nanoparticles, which are the dominative driving force to hydrocrack the asphaltenes.

Table 2 shows the viscosity and content of the four components (saturated hydrocarbon (SH), aromatic hydrocarbon (AH), resins and asphaltenes, SARA) of oil samples before and after aquathermolysis. Without catalyst or with only $\mathrm{NaNO}_{3}$, the viscosity of oil sample was only reduced by $23.6 \%$, where the variations of the four components were very slight, which suggested that there was no visible catalytic stimulation. Consequently, the cracking extent of heavy oil in the three reactions (without catalyst, with $\mathrm{NaNO}_{3}$, and with only microemulsion) is at a parallel level, leading to almost identical SARA distribution. The viscosity reduction should mainly result from pyrolysis, which suggests that the existence of $\mathrm{NaNO}_{3}$ has no promotive influence on aquathermolysis of heavy oil. When adding the pure microemulsion (organic solvent and emulsifier) to the reactor, the viscosity could be decreased by $65.7 \%$; however, the components almost remain intact, suggesting the viscosity reduction should be mainly ascribed to the emulsification effect. As the $\mathrm{CuO}$ nanoparticles, formed in situ from the CuME microemulsion, involve in the aquathermolysis, the viscosity of heavy oil was reduced by $79.5 \%$; simultaneously, the asphaltenes were reduced, while the SH contents were increased, which demonstrated that $\mathrm{CuO}$ could bring about irreversible transformation of heavy components into light ones. When $\mathrm{Cu}(\mathrm{OH})_{2}$-contained microemulsion participated in the catalytic aquathermolysis reaction, a viscosity reduction efficiency as high as $94.6 \%$ could be obtained. The viscosity reduction should be ascribed to the considerable decrease in asphaltenes which were reduced by $22.4 \%$ 
Fig. 2 TEM result of CuME after reaction (a without heavy oil and $\mathbf{b}$ with heavy oil)
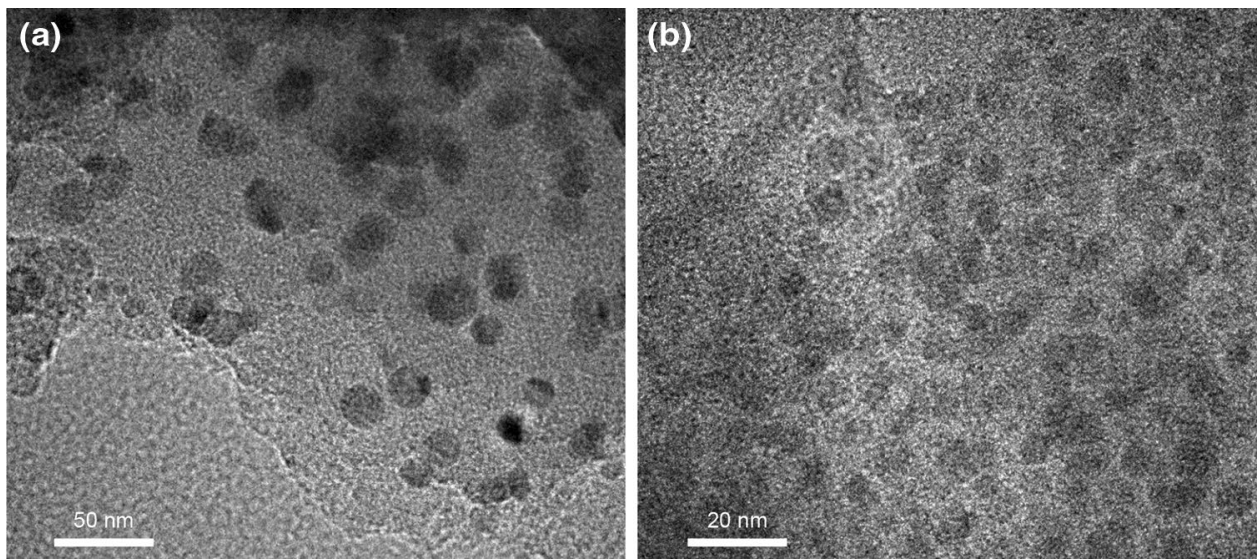

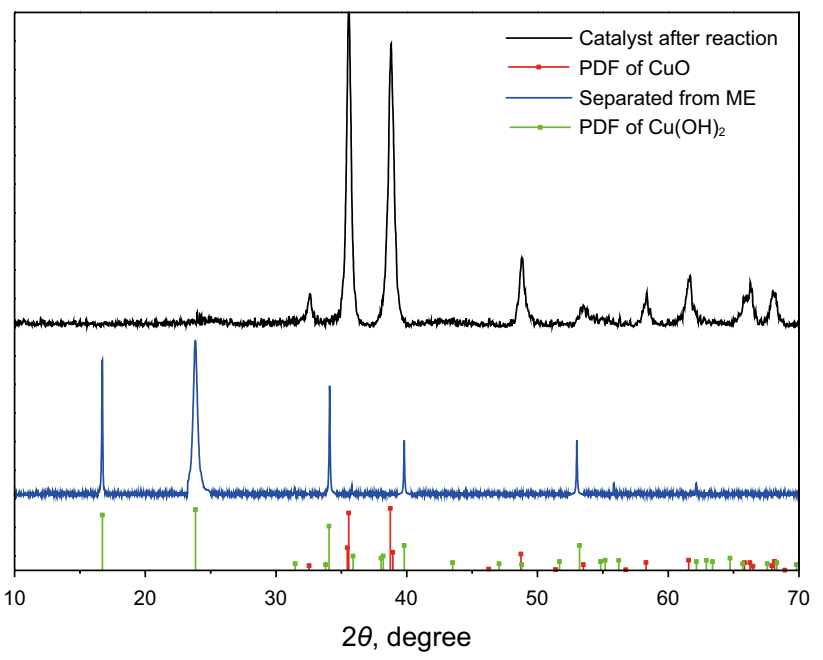

Fig. 3 XRD spectrum for catalyst after reaction and particles separated from $\mathrm{CuME}$ through the aquathermolysis reaction, leading to a corresponding increment of saturates by $23.2 \%$ as well as a slight increase in aromatics.

The two heavy components, from the original heavy oil and the post-reacted sample catalyzed by the $\mathrm{Cu}(\mathrm{OH})_{2}$ microemulsion, were next measured by ${ }^{1} \mathrm{H}$ NMR spectra to reveal the physicochemical variation information of resins and asphaltenes (Table 3). In addition, the elemental analysis of the two heavy components (Table 4) showed that the $\mathrm{S}$ and $\mathrm{N}$ heteroatoms in resins and asphaltenes were also reduced by a certain extent after aquathermolysis. For asphaltenes, the content of $H_{\mathrm{A}}(6.0-9.0)$ increased significantly upon catalytic aquathermolysis, indicating that the amount of un-substituted aromatics has been increased; such an increment was also observed for resins. This may originate from the partial elimination of heteroatoms $(\mathrm{S}, \mathrm{N})$ in the aromatic rings, which would lead to a ring-opening process. Simultaneously, the content of $H_{\beta}(1.0-2.0)$ and $H_{\gamma}$ (0.5-1.0) in resins and asphaltenes decreased, suggesting the

Table 2 Four components and viscosity of oil samples before and after reaction

\begin{tabular}{lccccc}
\hline & Viscosity, $\mathrm{mPa} \mathrm{s}$ & $\mathrm{SH}, \%$ & $\mathrm{AH}, \%$ & Resins, \% & Asphaltenes, \% \\
\hline Before reaction & $24,150 \pm 100$ & $16.45 \pm 0.03$ & $42.78 \pm 0.04$ & $21.01 \pm 0.05$ & $19.76 \pm 0.05$ \\
After reaction without catalyst & $18,450 \pm 100$ & $16.81 \pm 0.04$ & $42.85 \pm 0.03$ & $21.04 \pm 0.05$ & $19.30 \pm 0.03$ \\
After reaction with $\mathrm{NaNO}_{3}(\mathrm{aq})$ & $18,437 \pm 100$ & $16.84 \pm 0.03$ & $42.82 \pm 0.02$ & $21.02 \pm 0.03$ & $19.32 \pm 0.04$ \\
After reaction with microemulsion & $8283 \pm 70$ & $16.80 \pm 0.05$ & $42.79 \pm 0.05$ & $21.07 \pm 0.04$ & $19.14 \pm 0.04$ \\
After reaction with $\mathrm{CuO}$ & $4950 \pm 70$ & $18.86 \pm 0.04$ & $42.96 \pm 0.03$ & $21.15 \pm 0.02$ & $17.03 \pm 0.03$ \\
After reaction with $\mathrm{CuME}$ & $1300 \pm 40$ & $20.27 \pm 0.05$ & $43.14 \pm 0.03$ & $21.25 \pm 0.05$ & $15.34 \pm 0.04$ \\
\hline
\end{tabular}

Table $3{ }^{1} \mathrm{H}$ NMR of resins and asphaltenes: (a) before reaction and (b) after reaction with CuME

\begin{tabular}{lclll}
\hline Group composition, $\%$ & $H_{\mathrm{A}}(6.0-9.0)$ & $H_{\alpha}(2.0-4.0)$ & $H_{\beta}(1.0-2.0)$ & $H_{\gamma}(0.5-1.0)$ \\
\hline Resins (a) & 4.34 & 18.23 & 62.88 & 14.55 \\
Resins (b) & 11.61 & 19.08 & 55.17 & 14.14 \\
Asphaltenes (a) & 6.98 & 23.76 & 55.14 & 14.12 \\
Asphaltenes (b) & 13.93 & 22.62 & 49.79 & 13.66 \\
\hline
\end{tabular}


Table 4 Element analysis of resins and asphaltenes: (a) before reaction and (b) after reaction with $\mathrm{CuME}$

\begin{tabular}{llllll}
\hline Group composition, wt $\%$ & $\mathrm{C}$ & $\mathrm{H}$ & $\mathrm{S}$ & $\mathrm{N}$ & Average $N_{H} / N_{C}$ \\
\hline Resins (a) & $81.92 \pm 0.02$ & $10.07 \pm 0.03$ & $4.86 \pm 0.01$ & $1.17 \pm 0.02$ & $1.48 \pm 0.01$ \\
Resins (b) & $81.82 \pm 0.03$ & $9.98 \pm 0.01$ & $4.19 \pm 0.03$ & $1.04 \pm 0.02$ & $1.46 \pm 0.01$ \\
Asphaltenes (a) & $83.64 \pm 0.02$ & $8.25 \pm 0.02$ & $5.23 \pm 0.03$ & $1.11 \pm 0.04$ & $1.18 \pm 0.01$ \\
Asphaltenes (b) & $83.13 \pm 0.01$ & $8.33 \pm 0.02$ & $4.72 \pm 0.02$ & $1.02 \pm 0.03$ & $1.20 \pm 0.01$ \\
\hline
\end{tabular}

Table $5 f_{\mathrm{A}}$ (aromaticity), $H_{\mathrm{AU}} / C_{\mathrm{A}}$ (aromaticity condensation) and $\mathrm{BI}$ (branching index) of resins and asphaltenes: (a) before reaction and (b) after reaction with CuME

\begin{tabular}{llll}
\hline & $f_{\mathrm{A}}$ & $H_{\mathrm{AU}} / C_{\mathrm{A}}$ & $\mathrm{BI}$ \\
\hline Resins (a) & 0.29 & 0.67 & 0.12 \\
Resins (b) & 0.35 & 0.88 & 0.13 \\
Asphaltenes (a) & 0.45 & 0.50 & 0.12 \\
Asphaltenes (b) & 0.48 & 0.63 & 0.13 \\
\hline
\end{tabular}

decomposition of long side-chains. However, we mentioned that $H_{\alpha}(2.0-4.0)$ in asphaltenes decreases upon aquathermolysis, while the value in resins behaves inversely. This phenomenon indicates that some of the fragmented aromatics from asphaltenes might be transferred to resins, which could also be reflected by the slightly decreased $N_{H} / N_{C}$ of resins, and the slightly increased content of resins (Table 2). In contrast, after aquathermolysis, the $N_{H} / N_{C}$ of asphaltenes increases, which indicates that hydrogenation might take place in the catalytic reaction system.

Based on the improved Brown-Ladner methods (Suzuki et al. 1982), the structural parameters (the aromaticity $\left(f_{\mathrm{A}}\right.$, $\left.f_{\mathrm{A}}=\frac{\frac{N_{C}}{N_{H}}-\frac{1}{2 H_{t}}\left(H_{\alpha}+H_{\beta}+H_{\gamma}\right)}{\frac{N_{C}}{N_{H}}}, H_{t}=H_{\mathrm{A}}+H_{\alpha}+H_{\beta}+H_{\gamma}\right)$, the aromaticity condensation $\left(H_{\mathrm{AU}} / C_{\mathrm{A}}, \frac{H_{\mathrm{AU}}}{C_{\mathrm{A}}}=\frac{\frac{H_{\mathrm{A}}}{H_{t}}+\frac{H_{\alpha}}{2 H_{t}}}{\frac{N_{C}}{N_{H}}-\frac{1}{2 H_{t}}\left(H_{\alpha}+H_{\beta}+H_{\gamma}\right)}\right)$ and branching index $\left.\left(\mathrm{BI}, \mathrm{BI}=\frac{2 \times H_{\gamma}}{3 \times\left(H_{\alpha}+H_{\beta}\right)}\right)\right)$ were calculated and are shown in Table 5. Under the aquathermolysis of $\mathrm{CuO}$ nanocatalyst, the $f_{\mathrm{A}}$ and $\mathrm{BI}$ of the two heavy components increased due to the cleavage of side-chains and opening rings, leading to increments of saturates and aromatics (Table 2). Meanwhile, the enhanced $H_{\mathrm{AU}} / C_{\mathrm{A}}$ of both asphaltenes and resins points to a lower degree of aromatic condensation, indicating that both the fragmentation of large aromatic pieces as well as hydrogenation has occurred.

To detect the structural variation in light components, GC-MS measurement of SH, AH and gas was also taken. The content of n-alkanes (Fig. 4a) and monoaromatic steranes (Fig. 4b) are enhanced sharply after catalytic aquathermolysis with the $\mathrm{Cu}(\mathrm{OH})_{2}$ microemulsion. The retention time of the increased $\mathrm{SH}$ after aquathermolysis lies mainly in the range $30-70 \mathrm{~min}, \mathrm{C}_{16}-\mathrm{C}_{23}$ linear alkanes increased after catalytic aquathermolysis reaction, consistent with our speculation in the ${ }^{1} \mathrm{H}$ NMR and EA analysis. Meanwhile, monoaromatic steranes in AH increase, as shown in Fig. 4b, which could be ascribed to the aromatic debris split from the heavy components (resins and asphaltenes). The content of small molecules in the gas collected after reaction with CuME is more than that of without any catalyst, while the increment of small molecules resulted from the cleavage of heavy components and the breaking of long side-chain structures.

It is understandable that the microemulsion is composed of surfactants (SP-80 and TW-60) and solvents (isoamylol, diesel and a little water), which have rather excellent compatibility with heavy components. As a consequence, the $\mathrm{CuO}$ catalyst, transported by the microemulsion, can be homogeneously distributed in the heavy component. Catalyzed by the in situ synthesized $\mathrm{CuO}$ nanoparticles, long side-chains of the heavy components should be dissociated accompanied with aromatic ring opening and fragmentation, leading to considerably increased viscosity reduction.

\section{Conclusion}

In this work, we prepared $\mathrm{Cu}(\mathrm{OH})_{2}$ microemulsion for reducing the viscosity of Shengli heavy oil. The microemulsion can transfer and disperse the $\mathrm{Cu}(\mathrm{OH})_{2}$ precursors into the heavy oil phase; simultaneously, the $\mathrm{Cu}(\mathrm{OH})_{2}$ can be converted in situ into size-homogeneous $\mathrm{CuO}$ nanoparticles without agglomeration under the catalytic aquathermolysis conditions, which achieved a satisfactory viscosity reduction efficiency of $94.6 \%$. Under the aquathermolysis with $\mathrm{CuO}$ nanocatalyst, the heavy components (resins and asphaltenes) could be converted to light components ( $\mathrm{SH}$ and $\mathrm{AH}$ ) through the cleaving of $\mathrm{C}-\mathrm{S}$ bonds, breaking of long side-chain structures, opening rings as well as hydrogenation of unsaturated aromatics in heavy components. The results suggest that the in situ prepared ultra-dispersed nano- $\mathrm{CuO}$ catalyst provides a highly efficient and deployable choice for developing $\mathrm{Cu}$ or other TM oxide-based nanocatalysts for reducing the viscosity of heavy oil via catalytic aquathermolysis. 
Fig. 4 GC-MS spectra of M/Z

57 in $\mathrm{SH}$ (a), spectra of M/Z

253 in $\mathrm{AH}$ (b) and gas (c)

before and after reaction
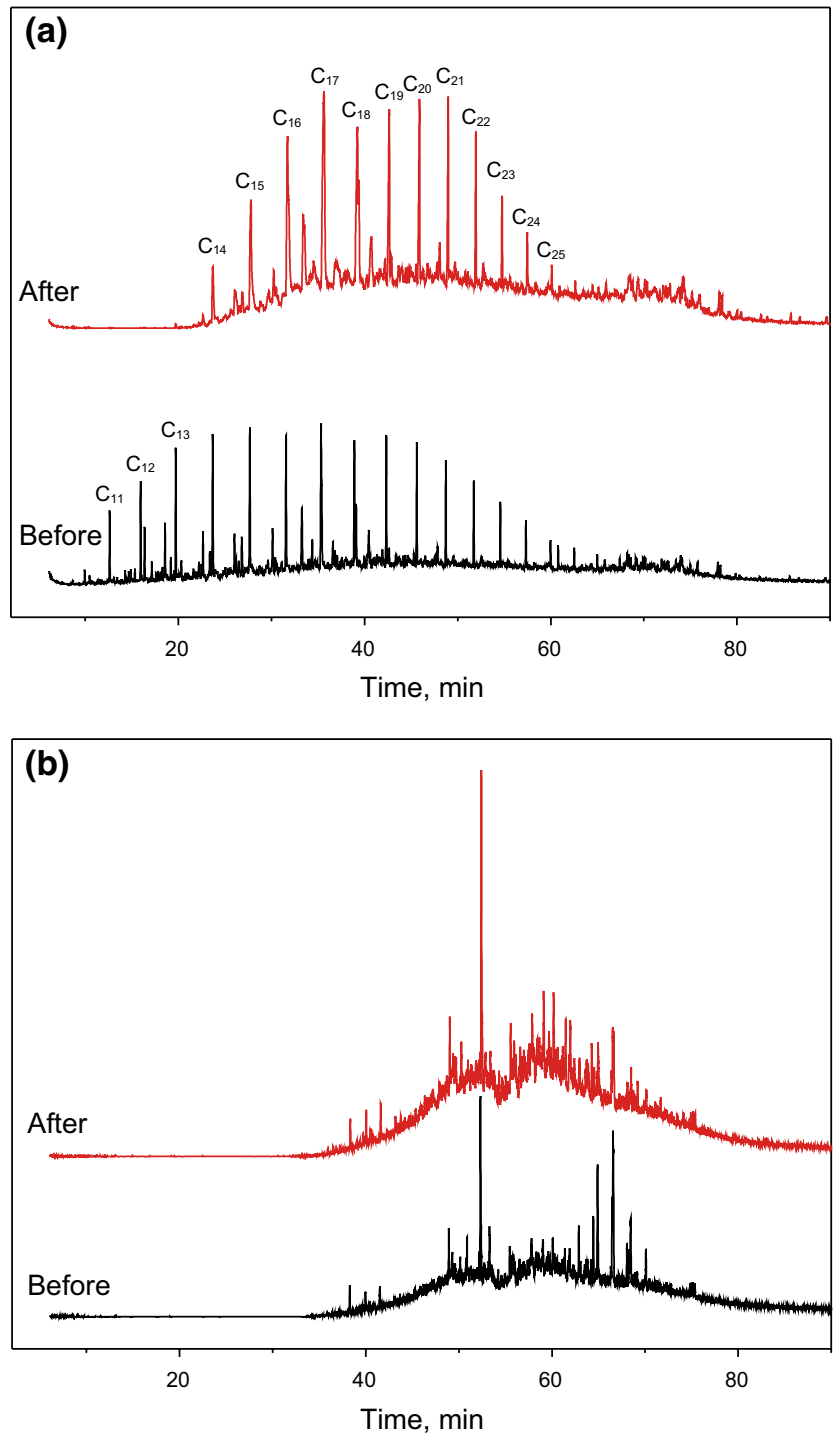

(c)

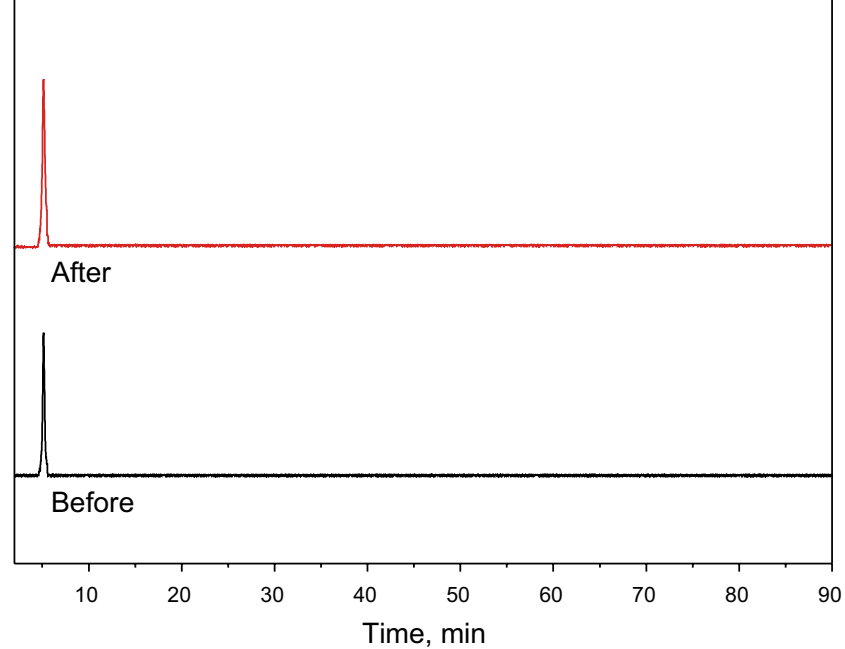


Acknowledgements This work was supported by PetroChina Innovation Foundation (Grant 2017D-5007-0211) and National Natural Science Foundation of China (Grant 51174179).

Open Access This article is distributed under the terms of the Creative Commons Attribution 4.0 International License (http://creativeco mmons.org/licenses/by/4.0/), which permits unrestricted use, distribution, and reproduction in any medium, provided you give appropriate credit to the original author(s) and the source, provide a link to the Creative Commons license, and indicate if changes were made.

\section{References}

Abdullah M. $\mathrm{Fe}_{3} \mathrm{O}_{4}$ /zeolite nanocomposites synthesized by microwave assisted coprecipitation and its performance in reducing viscosity of heavy oil. In: AIP conference proceedings. 2014. https://doi. org/10.1063/1.4866746.

Bano S, Ahmad SW, Woo SI, et al. Heavy oil hydroprocessing: effect of nanostructured morphologies of $\mathrm{MoS}_{2}$ as catalyst. React Kinet Mech Cat. 2015;114(2):473-87. https://doi.org/10.1007/s11144-014-0822-z.

Cao YB, Zhang LL, Xia DH. Catalytic aquathermolysis of Shengli heavy crude oil with an amphiphilic cobalt catalyst. Pet. Sci. 2016;13(3):463-75. https://doi.org/10.1007/s12182-016-0103-8.

Chao K, Chen YL, Li J, et al. Upgrading and visbreaking of super-heavy oil by catalytic aquathermolysis with aromatic sulfonic copper. Fuel Process Technol. 2012;104:174-80. https://doi.org/10.1016/j.fupro c.2012.05.010.

Chen Y, Wang Y, Lu J, et al. The viscosity reduction of nano-keggin$\mathrm{K}_{3} \mathrm{PMo}_{12} \mathrm{O}_{40}$ in catalytic aquathermolysis of heavy oil. Fuel. 2009;88(8):1426-34. https://doi.org/10.1016/j.fuel.2009.03.011.

Clark PD, Hyne JB. Steam-oil chemical reactions: mechanisms for the aquathermolysis of heavy oil. AOSTRA J Res. 1984;1(1):15-20.

Galukhin AV, Erokhin AA, Osin YN, et al. Catalytic aquathermolysis of heavy oil with iron tris(acetylacetonate): changes of heavy oil composition and in situ formation of magnetic nanoparticles. Energy Fuels. 2015;29(8):4768-73. https://doi.org/10.1021/acs.energyfuel s.5b00587.

Greff J, Babadagli T. Catalytic effects of nano-size metal ions in breaking asphaltene molecules during thermal recovery of heavy-oil. In: SPE annual technical conference and exhibition. Society of Petroleum Engineers; 2011. https://doi.org/10.2118/146604-MS.

Guo K, Li HL, Yu ZX. In situ heavy and extra-heavy oil recovery: a review. Fuel. 2016;185:886-902. https://doi.org/10.1016/j.fuel.2016.08.047.

Hashemi R, Nassar NN, Pereira Almao P. In situ upgrading of Athabasca bitumen using multimetallic ultradispersed nanocatalysts in an oil sands packed-bed column: part 1. Produced liquid quality enhancement. Energy Fuels. 2013;28(2):1338-50. https://doi.org/10.1021/ ef401716h.

Hashemi R, Nassar NN, Pereira Almao P. In situ upgrading of Athabasca bitumen using multimetallic ultradispersed nanocatalysts in an oil sands packed-bed column: part 2. Solid analysis and gaseous product distribution. Energy Fuels. 2014;28(2):1351-61. https://doi. org/10.1021/ef401719n.

Hou JJ, Li C, Gao H, et al. Recyclable oleic acid modified magnetic $\mathrm{NiFe}_{2} \mathrm{O}_{4}$ nanoparticles for catalytic aquathermolysis of Liaohe heavy oil. Fuel. 2017;200:193-8. https://doi.org/10.1016/j. fuel.2017.03.005.

Jiang DH, Xue JB, Wu LQ, et al. Photocatalytic performance enhancement of $\mathrm{CuO} / \mathrm{Cu}_{2} \mathrm{O}$ heterostructures for photodegradation of organic dyes: effects of $\mathrm{CuO}$ morphology. Appl Catal B Environ. 2017;211:199-204. https://doi.org/10.1016/j.apcatb.2017.04.034.

Kapadia PR, Kallos MS, Gates ID. A review of pyrolysis, aquathermolysis, and oxidation of Athabasca bitumen. Fuel Process Technol. 2015;131:270-89. https://doi.org/10.1016/j.fuproc.2014.11.027.
Li J, Chen YL, Liu HC, et al. Influences on the aquathermolysis of heavy oil catalyzed by two different catalytic ions: $\mathrm{Cu}^{2+}$ and $\mathrm{Fe}^{3+}$. Energy Fuels. 2013;27(5):2555-62. https://doi.org/10.1021/ef400328s.

Li GR, Chen Y, An Y, et al. Catalytic aquathermolysis of super-heavy oil: cleavage of $\mathrm{C}-\mathrm{S}$ bonds and separation of light organosulfurs. Fuel Process Technol. 2016;153:94-100. https://doi.org/10.1016/j. fuproc.2016.06.007.

Lu CH, Qi LM, Yang JH, et al. Simple template-free solution route for the controlled synthesis of $\mathrm{Cu}(\mathrm{OH})_{2}$ and $\mathrm{CuO}$ nanostructures. J Phys Chem B. 2004;108(46):17825-31. https://doi.org/10.1021/ jp046772p.

Mohammad AA, Mamora DD. In situ upgrading of heavy oil under steam injection with tetralin and catalyst. In: International thermal operations and heavy oil symposium. Society of Petroleum Engineers; 2008. https://doi.org/10.2118/117604-ms.

Muraza O, Galadima A. Aquathermolysis of heavy oil: a review and perspective on catalyst development. Fuel. 2015;157:219-31. https ://doi.org/10.1016/j.fuel.2015.04.065.

Nair S, Tatarchuk BJ. Supported silver adsorbents for selective removal of sulfur species from hydrocarbon fuels. Fuel. 2010;89(11):3218-25. https://doi.org/10.1016/j.fuel.2010.05.006.

Nezamzadeh-Ejhieh A, Amiri M. CuO supported Clinoptilolite towards solar photocatalytic degradation of p-aminophenol. Powder Technol. 2013;235:279-88. https://doi.org/10.1016/j.powtec.2012.10.017.

Noorlaily P, Nugraha MI, Abdullah M, et al. Ethylene glycol route synthesis of nickel oxide nanoparticles as a catalyst in aquathermolysis. In: Materials science forum. Trans Tech Publication; 2013. https:// doi.org/10.4028/www.scientific.net/msf.737.93.

Ovalles C, Rivero V, Salazar A. Downhole upgrading of orinoco basin extra-heavy crude oil using hydrogen donors under steam injection conditions. Effect of the presence of iron nanocatalysts. Catalysts. 2015;5(1):286-97. https://doi.org/10.3390/catal5010286.

Qin WL, Xiao ZL. The researches on upgrading of heavy crude oil by catalytic aquathermolysis treatment using a new oil-soluble catalyst. In: Advanced materials research. Trans Tech Publications; 2013. https://doi.org/10.4028/www.scientific.net/AMR.608-609.1428.

Ren RL, Liu HC, Chen Y, et al. Improving the aquathermolysis efficiency of aromatics in extra-heavy oil by introducing hydrogen-donating ligands to catalysts. Energy Fuels. 2015;29(12):7793-9. https://doi. org/10.1021/acs.energyfuels.5b01256.

Santra S, Tapec R, Theodoropoulou N, et al. Synthesis and characterization of silica-coated iron oxide nanoparticles in microemulsion: the effect of nonionic surfactants. Langmuir. 2001;17(10):2900-6. https ://doi.org/10.1021/la0008636.

Shokrlu YH, Babadagli T. Viscosity reduction of heavy oil/bitumen using micro-and nano-metal particles during aqueous and non-aqueous thermal applications. J. Pet. Sci. Eng. 2014;119:210-20. https://doi. org/10.1016/j.petrol.2014.05.012.

Shuwa S, Al-Hajri R, Jibril B, et al. Novel deep eutectic solvent-dissolved molybdenum oxide catalyst for the upgrading of heavy crude oil. Ind Eng Chem Res. 2015;54(14):3589-601. https://doi.org/10.1021/ ie5050082.

Suzuki T, Itoh M, Takegami Y, et al. Chemical structure of tar-sand bitumens by ${ }^{13} \mathrm{C}$ and ${ }^{1} \mathrm{H}$ NMR spectroscopic methods. Fuel. 1982;61(5):402-10. https://doi.org/10.1016/0016-2361(82)90062 $-X$.

Wang $\mathrm{H}, \mathrm{Wu} \mathrm{Y}, \mathrm{He} \mathrm{L}$, et al. Supporting tungsten oxide on zirconia by hydrothermal and impregnation methods and its use as a catalyst to reduce the viscosity of heavy crude oil. Energy Fuels. 2012;26(11):6518-27. https://doi.org/10.1021/ef301064b.

Wang JQ, Liu L, Zhang LL, et al. Aquathermolysis of heavy crude oil with amphiphilic nickel and iron catalysts. Energy Fuels. 2014;28(12):7440-7. https://doi.org/10.1021/ef502134p.

Wu Y, Li YF, Chen G, et al. Urea enhanced aquathermolysis of heavy oil catalyzed by hydroxamic acid-co(II) complex at low temperature. 
In: MATEC web of conferences. EDP Sciences; 2016a. https://doi. org/10.1051/matecconf/20166706038.

Wu J, Yang SY, Liu QZ, et al. Cu nanoparticles inlaid mesoporous carbon aerogels as a high performance desulfurizer. Environ Sci Technol. 2016b;50(10):5370-8. https://doi.org/10.1021/acs.est.5b03740.

Yang ZC, Liu XL, Li XH, et al. Preparation of silica supported nanoscale zero valence iron and its feasibility in viscosity reduction of heavy oil. Micro Nano Lett. 2014;9(5):355-8. https ://doi.org/10.1049/mnl.2014.0083.

Yusuf A, Al-Hajri RS, Al-Waheibi YM, et al. In situ upgrading of Omani heavy oil with catalyst and hydrogen donor. J Anal Appl Pyrol. 2016;121:102-12. https://doi.org/10.1016/j. jaap.2016.07.010. 